\title{
تقنيات العرض المسرحي واشتغالاتها في الامكنة المتغايرة
}

د. شيماء حسين طاهر/ جامعة بابل/ كلية القنون الجميلة/ قسم الفتون المسرحية م. أنيس حمود معيدي/ جامعة بابل/ كلية الفنون الجميلة/ قسم القنون المسرحية shima.h@gmail.com

\section{Tel. 07705383019}

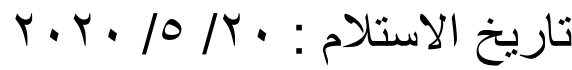

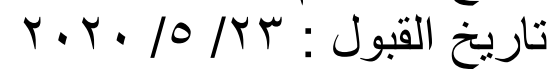

ملخص:

يعد مفهوم الهترتوبيا(Heterotopia) (الاماكن المتغايرة)عن كون مصطلح حديث استعمله لأول مرة الفيلسوف ميشيل فوكو وكان الهدف منه هو طرح امكنة تتغاير مع الاخرى وتتناقض معها والاعلان عن وقوف اليوتوبيا التي شملت الفلسفة المثالية ومن جاء بعده حتى ظهور الفلسفة المادية الا ان فوكو لم يعلن عن موت اليوتبيا(Utopia) وانما عمل على ايجاد البديل للمدينة او المكان الذي يعد موجودًا في اذهان المثاليين ولم يتحول الى واقع نهائيًا، حتى جاء الهتروتوبيا لتعلن عن وجود وامكنة مثالية موجودة بالفعل وان كانت خيالية، الا ان وجودها مطروح في المكان، حيث يرتبط المكان بغيره من الامكنة الاخرى يتناقض معها ، فالمكان هو عدة امكنة وليس مكانًا واحدًا وفق آلية ظهور مكان على حساب مكان اخر يكون ذا هوية ناشطة اكثر من المكان السابق. وقد تضمن البحث اربعة فصول احتوى الاول مشكلة البحث المتمثلة في الاستفهام الآتي: كيف يمكن ان تعمل تقنيات العرض المسرحي في تثكيل وابراز الاككنة المتغايرة وتناقضها واختلافها وفق

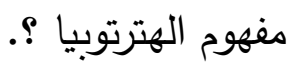

كما تضمن الفصل اهمية البحث من خلال تسليط الضوء على الامكنة المتغايرة ودراستها واشتغال فعالية التثنيات المسرحية فيها، كما احتوى الفصل على هدف البحث الذي اقتصر على تعرف كيف يمكن ان تعمل 


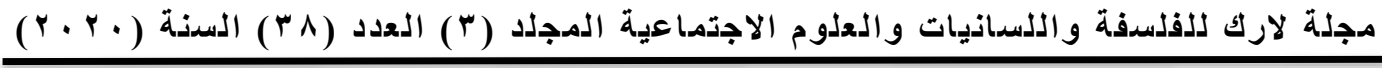

تقنيات العرض المسرحي في تثكيل وابراز الامكنة المتغايرة وتتاقضاتها واختلافاتها وفق مفهوم الهيترتوبيا. وشمل الفصل على حدود البحث التي تحدد زمانيًا عام بـ إب ومكانيًا العروض المسرحية المقدمة في بغداد، وأختتم الفصل بتحديد المصطلحات.

اما الفصل الثاني، فقد شمل الاطار النظري وتكون من مبحثين، اهتم الاول فيها يدارسه الأمكنة المتغايرة وتثكلاتها التقنية في المسرح العالمي، اما المبحث الثاني فقد عني بدارسه الأمكنة المتغايرة وتثكلاتها التقنية في المسرح العراقي، واختتم الفصل بالمؤشرات التي اسفر عنها الاطار النظري. بينما تضمن الفصل الثالث اجراءات البحث المتمثلة بعينة البحث و وادوات البحث ضمن منهج وصفي تحليلي، ليأتي تحليل العرض المسرحي (احلام كارتون) في حين جاء الفصل الرابع بالنتائج والتي كان من ابرزها:

1- تعمل التتنية على منح المتلقي امكنه متغايرة يتثكل من خلالها العرض وجمالياته ومنحه فضاءات تأوليه. r- تسهم التقنيات على منح امكنة متغايرة والتي يتثكل من خلالها العرض وجمالياته في خلق فضاءات تأويلية للعرض لكل فضاء علاماته فضاء افتراض وفضاء مجازي وفضاء العرض .

ثم اختتم البحث بالاستنتاجات والتوصيات والمقترحات وقائمة المراجع والمصادر . الكلمات الدالة: تقنيات، العرض المسرحي ، الامكنة المتغايرة. 
Techniques of theatrical presentation and its work in heterogeneous places Shaimaa Hussein Taher

University of Babylon - Faculty of Fine Arts - Section Theatrical Arts -Iraq

Email, shima.h@gmail.com, Tel. 07705383019

ANIES HAMOOD MIADEDI

\author{
University of Babylon - Faculty of Fine Arts - Section Theatrical Arts -Iraq \\ Email, anieshamood1@gmail.com, Tel.07825373014
}

\title{
Abstract
}

The concept of heterotherapy (heterogeneous places) resulted from the fact that a modern term was first used by the philosopher Michel Foucault, whose purpose was to present places that contrasted with each other and contradicted them and to announce the stand of utopia, which included ideal philosophy and later came until the advent of material philosophy, but Foucault did not announce the death But did work to find alternative to the city or place that is present in the minds of idealists did not become a reality, until the Htrotopia to announce the existence of an ideal place already exist and was fictional, but its presence is located in the place, where the place is linked to other places Whiten Spend it, it is several The place and not's locations one place according to the mechanism of the appearance of a place at the expense of another place be of active identity more than the previous place.

The research included four chapters, the first of which included the research problem of the following question: How can the techniques of theatrical presentation in the formation and highlighting heterogeneous places and contrast and different according to the concept of heterophobia? The second chapter, which included the theoretical framework and be of two subjects, the first interest is studied by heterogeneous places and their technical formations in the world theatre The current research aims at how the techniques of heterogeneous places and their technical structures can be used in the Iraqi theater, The chapter concluded with the indicators that emerged from the theoretical framework. The chapter included the "Limits of Search" which will determine the dates of 2013 and the venue of the theater performances presented in Baghdad The chapter concludes with the 
definition of terms The second chapter deals with the theoretical framework and is composed of two subjects.

The first one deals with the heterogeneous places and their technical structures in the world stage. The second topic is the study of heterogeneous places and their technical structures in the Iraqi theater. The chapter concluded with the indicators that resulted from the theoretical framework While the third chapter included the research procedures of the sample of research and research tools within the descriptive analytical approach, to come the analysis of theatrical play (Dreams Carton), while the fourth chapter came with results, which was the most prominent 1-The technique works to give the recipient the possibility of a heterogeneous form, through which the presentation and its aesthetics and granting its spaces.

2 - The techniques contribute to the granting of heterogeneous places through which the presentation and its aesthetics in the creation of interpretative spaces for the presentation of each space marks the space of assumption and space metaphor and the space of the presentation

Keywords: techniques, theater, heterogeneous places. 


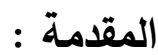

الفصل الاول

الاطار المنهجي للبحث

مشكلة البحث.

ان ايقاع العصر الحالي اختلف عن العصور الهالفة فقد امتازت تلك العصور بالهدوء، وتواتر وتعاقب في الاحداث والمشكلات

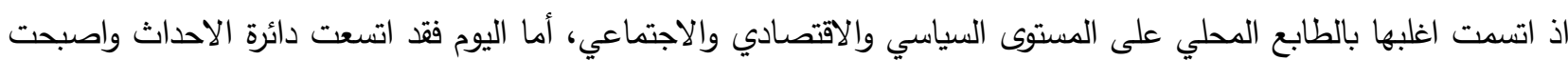
الأكنة توحد في المشاكل، فالعولمة جعلت من العالم (القرية التكنولوجية الصغيرة) ادى الى مشكلات تشمل الجميع دون خصوصية وذلك فان اي ازمة اقتصادية لابد ان تؤثر على الجميع دون استثناء يضاف الى ذلك التداخلات الثقافية والاجتماعية من خلال ما وفرته الفضائيات الرقمية واجهزة الحاسوب ثم الثبكة الدولية الانترنت، لقد ادى هذا التداخل في مناحي الحياة كافة الى تداخل كبير في الامكنة والازمنة وفق ما يجري من احداث مؤثرة في فيهما وفي الثقافات المحلية. وفي العرض المسرحي ووفق تلك الاحداث المعاصرة نجد الانعكاس ذاته يمثل انعكاس

للواقع الحياتي والمحلي والانساني على حد سواء، وهو من مميزات المرحلة الراهنة لذلك وليس عسيرًا ان تقدم عروضا مسرحية تتقل احداث الانسان المعاصر ، الراضخ لتلك المتغيرات حاضرا فيها كل التناقضات والاختلافات، وحضورا اكثر من مكان او مكان العرض المسرحي او مشهد مسرحي، لنقل تأثيراتها الواحدة في الامكنة المتغايرة وربما المتناقضة فقد يذوب الدكان، وهذا المكان الذي لا ملامح واضحة له، بسبب هيمنة امكنة كثيرة عليه هي اكثر فاعلية، فتجتمع الامكنة المتغايرة المتخالفة والمتناقضة في التثكيل والتكوين وفق غياب مكان ما او حضوره فلكل مكان مكوناته التقنية فنيًا، فالبيئة العراقية تختلف عن الاوربية، وبذلك سيكون الدور الفاعل الاساس عبر الامكنة المتغايرة، هويتها المميزة لها من خلال استخدامات التقنيات بكل اشكالها. لذلك تكونت مشكلة البحث والتي يمكن صياغتها بالتساؤل الآتي: كيف يمكن ان تعمل تتنيات العرض المسرحي في تثكيل وابراز الامكنة المتغايرة وتناقضاتها واختلافاتها وفق مفهوم الهترتوبيا؟.

$$
\text { اهمية البحث والحاجة اليه. }
$$

1- يسعى البحث الحالي الى توجيه عين المتلقي وذائتته الى اهمية التغاير والاختلاف في البيئة المشهدية المسرحية الواحدة، وما يثيره التغاير هذا في تعزيز العلاقات وتفاعلها الآني عند تواجد اثاث الأمكنة تقنيًا. r- ما توفره التقنيات الحديثة من التثكيلات البصرية من اسس جمالية وفنية تدعم التغاير في الامكنة، وتدعم هذا الاختلاف الجمالي المليء بالتوافقات الفكرية والفنية. 
يهدف البحث الحالي الى كيف يمكن ان تعمل تقنيات الأمكنة المتغايرة وتثكلاتها التقنية في المسرح العراقي. حدود البحث.

الحدود للزمانية : با • بام.

الحدود المكانية : بغداد

الحدود الموضوعية : العروض المسرحية التي امتازت بتتوع الامكنة وتغايرها في الوقت ذاته. مصطلحات البحث.

الهيتروتوبيا: وهي، اليوتوبيا، المتغايرة، التي تتيح وجود اللامكان في قلب المكان الحقيقي، ومثالها البسيط المرآة التي نرى فيها

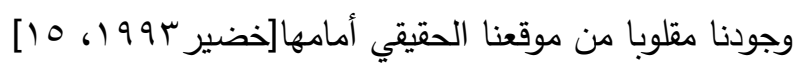

المتغاير : المتخالفان (هما المتغايران) مع ملاحظة حالة التغاير بينهما مثل الماء والهواء والنار والتراب[الحسني 90V1، rV0]. الامكنة المتغايرة: هي امكنة التي تكونت بفعل امتلاك المكان بهوية خاصة به تتتاقض مع غيره وقد تلغي غيره من الامكنة المتغايرة. الفصل الثاني الاطار النظري اولًا: الامكنة المتغايرة وتشكلاتها التقنية في المسرح العالمي. يعتمد المسرح بثكل اساس ثنائية مهمة واساسية تعد هي العصب الاساس كحاضنة الفعل الحدس المسرحي وهي ثنائية الزمان والمكان فأي حدث كما هو معروف لابد ان يتحدد بزمان ومكان، ان بلا زمان يحدد وقوع الاحداث وتصاعدها لا يمكن التفاعل مع الحدث مطلقًا لأنه سيبدو مبهمًا ، فضلًا عن كون الزمن يرتبط وبشكل بديهي بالمكان ، وبعاملي الزمان والمكان بحكم ان تأخذ الاحداث اشكالها ومضامينها وملامحها التي تميزها وتفرزها عن احداث اخرى "فالمكان هو المجال الفعال الذي يسمح للعرض المسرحي بالتحقق فإذا كان المكان هو الاحداثي الافقي من وجهة نظر هندسية فان الزمان لابد ان يكون هو الاحداثي العمودي وهذان الاحداثيان يثكلان المسافة الطبيعية التي يتحرك فيها العنصر البشري او الثخوص اي ابطال المسرحية

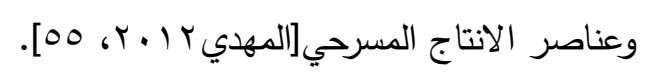

ومن الجدير الذكر ان ولادة مكان داخل مكان، او حضور مكان يعمل على تغيب مكان سابق في نفس البقعة هو الاساس، فظهور ملامح مكانية وغياب اخرى يعتمد على محاولات ليست باليسيرة او القصيرة الزمن، بل هي محاولات نجاح واخفاق حتى 
يصل المخرجين في العالم الى الوصول الى نوع جديد من التعبيرات المسرحية والفنية المتعلقة بفضاء العرض المسرحي وعناصره التقنية التي تسعى الى تقديم رؤيا اخراجية تاريخية ومهمة.

لقد بدأ العمل على المكان المسرحي بفعل تطور التقنيات الهائلة في عصرنا الراهن مما اثار المخرجين الى البحث عن المكان المتغاير والفعل المتغاير عما سبق اذ ان الامكانات اصبحت متوافرة وداعمة للرؤيا الاخراجية في فتح مكان لم يكن يستطيع المخرج المسرحي ساقًا ان يدخل مسالكها ، فالضوء والموسيقى والتثكيلات البصرية جعلت من العرض المسرحي عرضًا يعتمد التشكيل بشكل كبير لاسيما بظهور مفاهيم واشتغالات السينوغرافيا الحديثة فالإخراج المسرحي لم يعد فن اقامة بيئة ولكنه لغة تثكيل في الفراغ مثل التي للرقص او الموسيقى[العبودي لذلك فإن المكان اصبح تركيبًا يؤدي الى وحدة العرض المسرحي وفق

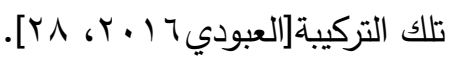

ان المكان لاى المخرج والمصمم المسرحي (ريتشارد شيشنر) صاحب المسرح البيئي ، المسرحي يختلف كل الاختلاف عمن سبقه ، فالعرض المسرحي يشكل مجموعة انتقالات من وينتقل من الفضاء الساكنة الى الفضاء المتاقض تمامًا والتغاير ، فالمكان لايه يرتبط بالأعضاء الجنسية وهو يعد ذلك تطورًا يمتلك جانب الايجاب لا السلب ومن جانب اخر فهو يعمل في عروضه الى الاعتماد على البناءات الخرافية والتصورات الدينية وشكلًا متعدد بحيث لا يعمل على تقويض الصورة، الا من الناحية الجنسية ولا من الناحية الدينية، كما ان(شيشنر ) يسعى الى صناعة بيئة مسرحية مناسبة للنص وافكاره ، ولذلك فهو يقوم باستخدامات متعددة في توظيف تقنيات العرض بطريقة الاعتماد الكلي عليها وليس بكونها عناصر مساعدة في اظهار الامكنة

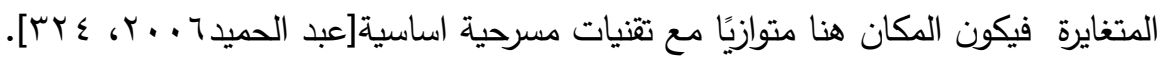
وبناءً على ذلك فإن الاسس التي اعتمدها (شيشنر) بشكل كبير هو الفضاء المتحرك بمعنى تغاير الاككنة، وهو امر مفروغ منه في اسلوبية (شيشنر) الاخراجية، ان هذا المكان يجب ان يكون مكتثفًا وجديًا، وتتم عملية القلب لأي مكان، ملعب كرة سلة، كراج للسيارات حلبة مصارعة، المهم ان يكون المكان متغايرًا وقابلًا للتغاير كذلك اثناء العرض، وبذلك يتم اختبار المكان على اساس قابلية المرنة للتغير والتغاير كما حدث ذلك في مسرحية (ديونيسوس 79) تلك المسرحية التي اعاد من خلالها مسرحية يوربيدس (الباهوسيت) برؤية معاصرة وجديدة حيث قدمها في كراج للسيارات، ويدخل الجمهور وكأنهم يدخلون الى طقس او مكان سري، فتضضي الممرات الى مكان واسع يحتوي منصات خشبة بلونها الاساس (غير مصبوغة)، وليس هنالك مكان جلوس المتفرجين مع تثكيلات المكان البصرية المتحولة يأكل مرة بحيث ينتقل المتقرج في عديد الامكنة المتغايرة في المكان الواحد (كراج السيارات).

ومن الجدير بالذكر إن الامكنة المتغايرة لا تختص برؤية مخرج وتتطلق من بيئته هو، اي ان هذا ليس شرطًا فقد يقدم المخرج المسرحي العالمي الغربي اجواءً وامكنة شرقية والعكس صحيح اي ان يقدم المخرج القروي اجواء وامكنة غربية وذلك ما يشير الى متغايرات الامكنة من اجل خلق تعددية مكانية وتثكل هتروتيويا مبنية اساسًا على لغة المكان وغياب لغة اخرى لمكان فاقد 
لقد حصل ذلك لاى المخرجة الفرنسية (اريان منوشكين) التي تقول: منذ طفولتي وانا منجذبة لاجواء الشرق والثرق الاقصى خصوصًا اذ ترى فيه منابع الفن المسرحي، لذلك فقد قدمت (طرطوف) لمولير بصيغة اسلامية والازياء والامكنة كانت تثير الى اوائل القرن في الثرق، وفي مسرحية (طبول على السد) تتتهي المسرحية يلم محرك الدمى ومحرك دمى اخر يرتدي زي غريب ، يلم الجثث (جثث الدمى) الموجودة في النهر بعد فيضانه ، حتى يستطيع روايتهما مرة اخرى لتجنب المآسي ان دور الفن هو في

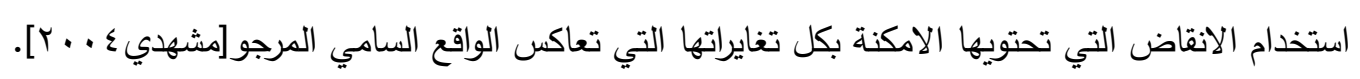

ويجب ان ننوه انه في مسرح (منوشكين) تكثر استخدامات الامكنة المتغايرة وبشكل لافت للنظر لاسيما في مسرحية (IV^9) تلك المسرحية التي سعت فيها الى توريط المتفرج في الاحداث المسرحية من خلال وجوده لا قيمة التصاعد الدرامي حيث تم تقسيم البناية الى نصفين ، وتم وضع مدرج خثبي كمكان للجمهور، ثم كانت (منوشكين) الى تقسيم المكان الى خمس امكنة من خلال وضع خمس منصات خشبية كان ارتفاعها حوالي (0 أقدام) مع وضع كثافات واضاءة غير مبالغ بها والى مشاعل

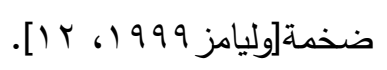

ولتوضيح ذلك انه في مسرحية (1 ( V^9) قدمت (منوشكين) احتفالًا مسرحيًا ذي بؤر متعددة ليصنع المسرح الشعبي والتي من خلالها استعرضت تاريخ فرنسا حيث تأثيرات المسرح الآسيوي وتقنياته حيث اختلاف الامكنة من عرض لأخر بل وحتى داخل العرض المسرحي الواحد فانه يضج بعديد الامكنة المتداخلة المتباعدة ، وفق قواعد التناقض والحضور والغياب لهويات الاككنة. ولذلك فإن اهم ما يمكن الاشارة اليه في تغاير الامكنة لاى( اريان مونشكين) حيث تجلى ذلك بشكل واضح في مسرحية ( اذ تم وضع اربع منصات للتمثيل، كل منصة تقدم شكلً مغايرًا عن الاخر بحيث يجد المتفرجين أنفسهم أمام اربعة امكنة متغايرة يكون للمتلقي حرية اختيار المنصة التي سيثاهد عليها احداث فرنسا، وذلك ما سيعني ان التغاير في المكان قصدي وبشكل جوهري عرفته مسرحية (1 V^9)، ولذلك فالأمكنة المتغايرة تمنح العرض ابعاد وجمالية وفضاءات كبيرة للتأويل والقراءة عند المتلقي.

ان العرض المسرحي يشكل عند (فورمان) كولاجًا متنافرًا يسعى لهدم وحدة المكان والحدث، باستخدام تقنيات العرض المسرحي هو الاخر بثكل متغاير جدًا، فالعرض نص مسرحي، والنص عرض مسرحي، فالطقسية لم تغادر امكنة الخشبة او العرض عند فورمان ، ويعمل على استثارة خيال المتلقي والخيال هنا كبديل لمنطق العقلانية او العقل ، فالعقل لدى فورمان فقد قيمته وجاء الخيال بديلًا عنه ، لأن العقل سبب الدمار الذي لحق بالحضارات لذلك فان الخيال اكثر حضورًا واكثر تعبيرًا لاسيما وهو يمتلك الفضاءات الثاسعة للتأويل والاندماج ، فالتحرر في مسرح (الهستيريا) هنا هو بأطلاق العنان لخيال المتلقي وخلاصة من تحجيم

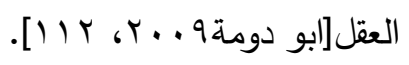

ولعل من المناسب ذكره ان نهج فورمان في آلية استخدامه للأمكنة المتغايرة بشكل عمدي وواضح في مجموعة اعمال مسرحية منها (اشباع رغبات الجماهير) ، اذ قدم فورمان الكثير من عناصر التقنيات البصرية الاساسية في الضوء والزي والموسيقا 
والمؤثرات الصوتية التي عدت عوامل غير مساعدة ، فضلًا عن جزيئات الموضوعات الكثيرة في العرض الواحد والتي تبتغي الانتقال المستمر من مكان الى اخر مختلف ومتناقض.

ومن زاوية اخرى ان العرض المسرحي عند فورمان يحوي في فضاءاته على التناقضات التي لا تلتحم ولا تتقى، وكذا عديد الامكنة المتناقضة التي تؤسس لهتروتوبيا تضم العرض بكلتيه فاستخدام الشرائع على شاشة عرض هو تفعيل لأمكنة خارج العرض والاشرطة المسجلة صوتيًا فضلًا عن الملضصات التي اعتمدت تكنيك الفلاش السريع ويقسم فورمان المسرحية الى لى وحدات - مشاهد صغيرة متسارعة - متباطئة - تعمل على خلق امكنة متنوعة متناقضة - متغايرة - سعيًا منه لتفعيل الجانب الخيالي لاى المتلقي.

أما المخرج (روبرت ويلسن) الذي يعرف مسرحه بمسرح المتتاقضات المتعددة، ويوصف بأنه اسفنجة اساطير حيث تتميز اعماله بالآستاتيكية الصورية والخطوات البطيئة والتناقض في مسرحه حيث يرتبط بفكرة التتاقض وهو الاساس حيث تتشكل صور وتتحل وتتداخل مع اشياء اخرى وتتشظى وتعاد تشكيلها.

وعندما صمم(روبرت ويلسن) مسرحية (خطاب الى الملكة فكتوريا) للعرض في منطقة برونسيوم حيث استخدم فيها ديكورات ضخمة معقدة والمسرحية ليس فيها قواعد سرد بداية ووسط ونهاية حيث تكون الخشبة فيها مقسمة بعدة مناظر مسرحية ينضم اليها الناس وادخال عدة تقنيات توحي بتغار المكان مثل رأس التمساح او صخرة وممثلين يحملون ارقام بدلاً من الاسماء فعملية التحويل المستمرة دائمًا يغير من طبيعة مكان العرض المسرحي ويكسبه تغايرية[كاي 999 (1، 97]. كما ان ويلسن استخدم كل التكنولوجيا ومؤثرات المسرح التقليدي بخلق الايهام بالمكان المتغاير فقد اعتمد على تصميم ملابس وادوات والاكسسوارات التي توحي بالغرابة والتتاقض حيث استخدم الاقنعة والحقائب والعربات وغيرها بطريقة تمنحها بعدًا ومعنى جديدين بعد ان تتغير وظائفها الواقعية وكذلك الاعتماد على ممثلين غير محترفين للوصول للعفوية في الحركة والصورة وعندما اخرج مسرحية الحلم للكاتب السويدي اوجست ستران بيرد فقط اخرجها على شكل لوحات فنية ساحرة وطريقة سينوغرافية

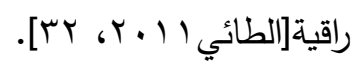
ثانيًا: الامكنة المتغايرة وتثكلاتها التقنية في المسرح العراقي. ان انتقائية مجموعة من المخرجين في المسرح العالمي ممن عمدوا الى تفعيل الجانب المتغاير للمكان (الهتروتوبيا) وفي المقابل، فإن المسرح في الوطن العربي الذي شأنه شأن المسرح العالمي سعى الى حضور الهتروتوبيا في فضاء اعمالهم المسرحية ، وبما ان المسرح العراقي يشكل الجزء الحيوي والمهم في المسرح العربي لذلك ستكون انتقائية اختيار المخرجين حاضرة كذلك. ويعد مسرح قاسم محمد الموجه الجديد في المسرح العربي، موجة التجديد والتأصيل او البحث عن هوية مسرح عربي منذ نهاية السبعينات حتى ما بعد منتصف الثمانينات من القرن الماضي وهو يجمع بين الاخراج والكتابة للمسرح ، اذ اخرج اعمال تراثية او 
ان موضوعاتها مستمدة من التراث ومنها مسرحيات (طال حزني ومروري في مقامات الحريري) و(بغداد الازل بين الجد والهزل)

$$
\text { ومسرحية (كان يا ما كان) و (انها امريكا) و (الباب) }
$$

ويتضح اعتماد الامكنة المتغايرة في مسرح قاسم محمد في مسرحية (انها امريكا) حيث المكان (الولايات المتحدة الامريكية) وحضور ثيمات (الموت - الرعب - الجوع) فيفتح العرض بأضراب في مستثفى (برونكس لتكوين) في نيويورك احتجاجًا على موت الفقراء السود والبيض بسبب الاهمال المتعد، وبعد ذلك ينتقل المكان الى اخر متغاير بكل شيء حيث الكونغرس الامريكي وهو يناقش اسباب الجوع والمرض ومع امتداد الحوار يتضح لنا العزلة السياسية التي يعيشها الكونغرش عن مواطنيه. لقد نم طرح مشكلة التمييز العنصري من خلال موت العامل(فيليب شاكوان) الذي يتعرض لحادث دهس في سيارة دون ان يتلقى العلاج المناسب فيموت ، وتدور أمه في الازقة والثوارع وحيث المكان المتغاير الواقع الحياتي للفقراء الذين يستجدون في الشوارع ويلتحفون الارصفة، فأم الميت تتسول في الثوارع لتحصل على المال الكافي لدفن ابنها، ث ينتقل العرض الى مكان متغاير جديد هو بين العامل (بيل بورني) الذي يعاني وزوجته من مرض ابنهما الصغير ، ويفدم قاسم محمد هذا العرض عبر استحضار الكثير من الامكنة التي اتضحت من خلال مشاهد قصيرة جدًا او مختزلة هدفها الكثف والتعرية بانتقالات متوازية حيث اجتماع الكونغرس في وقت كان فيه الاضراب في المستثفى على اوجه ، ثم تسول المرأة في الثوارع وبعدها الطفل المريض وحيرة امه

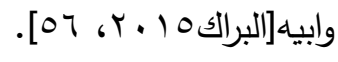

وفي ضوء ذلك ان مسرحية (انها امريكا) تمثل انعكاسات مهمة للأمكنة المتغايرة في العرض المسرحي الواحد، حيث كثرة الامكنة المتتاقضة وعدم التحامها او ارتباطها الفكري بأي شكل من الاثكال فمن اضراب الاطباء في المستثفى الى جلسة الكونغرس مرورًا (بفيليب شاكوار) المتوفي الى بيل بورين والد الطفل المريض في بيته ، ثم (سان جونسن ومستر بوندوس وويك مبيسون) وحضور الهندي الاحمر صاحب المكان الاصيل والذي اصبح هامشيًا بكل امكنته وهويته وحتى النهاية فنشاهد هنا ان الامكنة المتغايرة كانت اساسًا في تثكيل العرض المسرحي والتعبير عن هموم ساكنيه ومنتمون اليه.

أما بالنسبة للمخرج صلاح القصب صاحب مسرح الصورة فقد كان يرفض تقاليد المسرح التقليدي السائدة وكان يسعى الى حفريات في امكانية استثمار الخيال والتأمل المعرفي في تحفيز الطاقة الكامنة في الكلمة ، ولديه ان مسرح الصورة هو نوع من التداعيات الصوفية والاحلام السريالية المتهشمة، ويرى في الصورة انها في مختبرها السري تنقل الكلمات وصورها كالثعرية البلاغية السمعية الى صور مرئية تعتمد التثكيل البصري اساسًا في تكوين المكان والحدث، ووفق هذه المفاهيم اخرج العديد من المسرحيات، وفي احد عروضه المسرحية الذي امتاز بتعددية الامكنة المتغايرة وفق مفاهيم مسرح الصورة نجد انه في العام

$$
\text { . } 191 \text {. }
$$

وهنا لابد من بيان ان القصب تلاعب بالنص وشكله، فجاء على عنصر الاطاحة بالنص وتثكيله وفق مقتضيات مسرح الصورة ، فلا توجد جريمة قتل وانما هي محض وهم صاغه خيال هاملت المصاب بالانفصام الثخصي والملكة تعاني من هيمنة روح شريرة، فصار هاملت حسب عرض القصب يسير بخطين الاول تحت سيطرة الروح الشريرة ، والثاني بمعزل عنها، وعندما يكون 
تحت تأثير الروح الثريرة يظهر هاملت متلبيًا شخصية شاب افريقي بدائي وقد مثل هذه الثخصية ممثل أسود، وكذلك اوفيليا مثلتها ممثلة سوداء، وهنا يكون هاملت خارج تأثير الروح الثريرة يعود الى طبيعته وشكله الابيض (وقد مثل هذه الثخصية ممثل ابيض) وكذلك في هذه الحالة تكون (اوفيليا ممثلة بيضاء

ومن اجل ذلك ولغرض تثكيل المكان الواحد الذي تعود مرجعياته الى امكنة متغايرة، وظف المخرج في فضاء العرض اشكالًا ورسومًا بدائية (مكان الانسان الاول، المكان كهف في هذه الحالة)، ثم اشياء مستوحاة من الفنون البدائية (الرقص والطبول) وأوان فخارية وحيوانات خرافية وهنا المكان خيالي مستوحى من الموروث الشعبي، وهو ذلك كان يحاول الاشارة الى شخصياته كونية من الممكن ان توجد في اي عصر او مكان فقد جردها من ملامحها البيئية التي تثير الى الراهن المغلق، بل الى الفضاءات المكانية المفتوحة على عديد الامكنة[علي • [ ـ ب، T11]].

ووفق تلك الرؤية يكون هنالك عالمين: القرية هاملت الابيض المتزن العقلاني، والعالم الافريقي هاملت الأسود، وبذلك يفتح القصب العرض على امكنة متغايرة متتاقضة، ابتداءً من البداية حتى الكولنيالية حيث القرية الابيض المهيمن، وصورة الافريقي الأسود البدائي الساذج المتخلف، لذلك فإن الرجل الابيض الذي اسسه القصب يمثل البعد الاستعماري، اما الافريقي فهو المستلب، فقد سلبته القوى الثيطانية هويته وبيئته، وحولته الى اداة، وبذلك يكون حضور الامكنة المتغايرة اساسًا في هذا العرض، فمن الاثكال البدائية التي تثير الى امكنة متغايرة مع وضع القرية المتحضر المتقدم، انهم مكانين متناقضين بكل معاني التناقض، ويرابط بين الامكنة هي الروح الثريرة التي تهيمن على الامكنة لكنها في المملكة.

إن المسرح الذي يعتمد الاككنة المتغايرة (الهتروتوبيا) لا يمثله جميع المخرجين في العالم بل هو خاضع لشروطه الخاصة، ويسعى الى ضرب التقليدية في المسرح، وبالتالي يقتضي تحولات مكانية تعبر عن المتناقض والمتثظي، حيث الاساس في ذلك هو غياب القوانين المانعة للتداخل الحضاري الزماني والمكاني، وبذلك فقد سعى المخرجين الذين عمدوا الى ضرب السائد والمألوف الى ادراك هذه الحقيقة، فاجتماع التتاقضات الفكرية والمكانية امر جائز في العرض المسرحي واصبح يعبر عن عصرنا الحالي بكل اشكاله المتغايرة. المؤشرات التي اسفر عنها الاطار النظري. تبعًا لما تقدم في الإطار النظري، تم تحديد جملة من المؤشرات، وهي كالآتي: ا- تشتغل التقنيات المسرحية في الامكنة المتغايرة وفق جدلية الحضور والغياب، وخلق هوية وممثل والمكان r- تختلف اشتغالات التقنيات المسرحية في الاككنة المتغايرة وفق بنية الصورة البصرية للمكان المسرحي بالهدم والبناء والثابت والمتحول والمرئي واللأمرئي في العرض المسرحي والتقنيات المسرحية. r- للتقنيات المسرحية في الامكنة المتغايرة بنى ودلالات ومعاني مختلفة ومتتوعة، وفق لتتوع وتعدد الطرح الفلسفي للرؤية الاخراجية. 
ع- تتخذ التقنيات المسرحية في الامكنة المتغايرة بنى فنية وتقنية وجمالية في تأسيسها كسرد تثكيلي تعدد الامكنة في المكان الواحد .

ه- للخيال مقدرة في ايجاد امكنة متغايرة تتعلق بذات المتخيل وهي امكنة لا مرئية محايدة، ترتبط بالأمكنة المتغايرة فنيًا يعتمد على خيال الفنان في تثكيل التغاير المقصود فنيًا، وتسهم التكنولوجيا في تفعيل وتحولات الامكنة المتغايرة. الفصل الثالث

$$
\text { اجراءات البحث }
$$

عينة البحث: مسرحية (احلام كارتون) تم اختيارها بطريقة قصدية وذلك للمسوغات الآتية: 1- إنها الاقرب في موضوعة البحث وهدفه . r- عرض مسرحي يسمح بتعدد القراءات في امكنة متغايرة . ادوات البحث.

1- المؤشرات التي اسفر عنها الاطار النظري بوصفها اداة البحث المعتمدة في اختيار العينة وتحليلها. r- (- مشاهدة عينة البحث(اقراص ليزرية). r- المصادر المتعلقة بعينة البحث. منهج البحث: تم اعتماد المنهج (الوصفي) في تحليل العينة، تبعًا لما تمليه عليه طبيعة البحث الحالي. تحليل عينة البحث. مسرحية (احلام كارتون) تأليف، (كريم شغيدل) اخراج، (كاظم النصار) مكان العرض العراق، بغداد، المسرح الوطني. يندرج عرض مسرحية (احلام كارتون )الى ما يسى (البؤرة السياسية) الذي تمتزج فيه الكوميديا السوداء والذي من خلاله يعمل العرض على تعرية الواقع العراقي وانماطه الثقافية حيث اعتمدت التقنيات المسرحية الثابتة والمتحركة بثكل اساسي في صنع الهتروتوبيا، سعت الى الكثير من التتاقضات في الامكنة وكذلك لصنع يوتوبيا مغايرة لمفهوم اليوتوبيا والخلاص من مثالياتها. ان ثنائية الواقع المعاش والحلم الذي يشكل مكانة مطلوبًا مهمًا في هذا العرض هو اساس انطلاق العرض واهدافه من خلال طرح اربعة نماذج عراقية تعود الى شرائح اجتماعية مختلفة تدور احداث النص في مكانين متغايران المطار والطائرة وهي تحلق بهم ، اربعة انماط ثقافية يجدون انفهه في رحلة سفر في طائرة يريدون ان يتخلصوا من 
وضع وجدوا انفسهم محاصرون فيه، يشعرون برغبة الى الطيران من واقع مأزوم، كل واحد من هؤلاء يشكل نمط او شريحة من المجتمع جمعهم هم السفر ، يضعهم النص على مشرحة النقد.

(مغنية) تريد ان تجد ذاتها تحدوها رغبة في الهروب والطيران من الواقع الذي سبب بتدمير احلام لم تحقيق، وقد جاءتها الفرصة للانطلاق والبحث عن ذواتها، فهي تريد ان تمضي لتحقق احلامها الضائعة احلامها التي تيبست لذا فهي ترغب بالانفلات، تصرخ بدهاه تريد ان تطير لتحقق حلم حياتها حيث تصرخ بدهشه (اريد ان اطير لازم اغادر هذا المكان) في هذا المكان الذي سجن احلامها، العمر يمضي دون ان تحقق شيء فهي رغبة في الانفلات.

والثي ذاته الذي يعشه (الرجل المثقف) الذي شعر بانه خسر كل شي ضاع حياته بالسجون هو المثقف الذي تربطه علاقة بالكتب والثقافة هو الذي كان يحلم بتغير هذا الواقع الذي يضطهد العامل مثل كل المثثقين اليساريين الذين تدمرت حياتهم في ظل الأنظمة الدكتاتورية ،هو المثقف الذي يريد ان يرتوي من انجازات الحضارة ويشبع من الفن، ان يعيش حياته بعيدا عن تلك الخيبات التي عوقت تقكيره، فهو نسق يمثل المثقف اليساري الذي دفع ثمن باهض من اجل مبادئه والتزامه، اذ هو الان يرد ان يجد ذاته ويطير ، ما هناك فرصة للطيران.

(الرجل العسكري) الذي يمثل ذاكرة الحرب انه الجيل الذي رهن كل حياته لحروب خاسره حروب تسكن وتعيش في ذاكرتتا الجمعية ، ها هو الان قد وجد فرصة الانفلات والطيران من هذا الواقع الذي سيج حياته بحروب، فهو يريد ان يعوض خسائره الكثيرة يريد ان يطير ان يحقق احلامه التي وأدتها الحروب ، يجد نفسه في الموقف انها فرصة الانفلات والطيران الى حياة بعيد عن شبح الحروب نعم هو يريد ان يعيش ما تبقى من حياته ،وليشبع رغباته دولارات ، سفر ، وعبث وحياة ماجنه بعيدة عن هول الحروب

الثخصية الرابعة المتمثلة (برجل الدين) والذي يهيمن عليه النسق الديني هو الاخر قد وجد فرصة للطيران وتحقيق ما يصبو اليه انه يريد ان يطير لذ فهو يعدد على الاتكاء على النسق الديني الذي لتحقيق غاياته واهدافه فهو يبحث عن الحيل الثرعية لتمرير خطابه مدفوعا بثقافة العنف ونبذ الاخر والاحتيال عليه بينما هناك رجل محرك الحدث (يمثل الأنا) التي تتحكم بكل شيء آنا تمارس حضورها على الجميع هذا هو المسار الذي تحرك فيه النص وهو تسليط الضوه على الحالة العراقية والخوض في جذورها وتحولاتها.

لقد تحرك العرض ليلامس تلك الفضاءات التي بثها النص وحلق بها عليا وان كل هذه الثخصيات لها احلامها الخاصة بها التي تسعى الى الوصول اليها انهم في مكان تجتمع فيه المتناقضات رجل الدين مع الفنانة وهي علاقة ينظر اليها رجل الدين بكونها اثيمة ، وعلاقة الفنان برجل الدين يعني لها التقيد التحجيم والقانون، ثم علاقة المثقف مع الاخرين في علاقة انعزال، اي عدم تلاقي فهو كما الواقع يعيش في باطن كتبته، وكذلك الجندي الذي تمسك بلباس العسكرية للكثرة الحروب بويلاتها، انها علاقات مفككة اجتمعت في مكان بعد ان جمعهم ك حسب حلمه في المكان الذي يريد الوصول اليه.ل 
لقد عملت التقنية من خلال الضوء والموسيقا والاكسسوارات ومكياج ثم قطعة الديكور المتحركة والمتحولة الى خلق امكنة متغايرة داخل فضاء واحد او مكان واحد، سابق لها بحيث يفقد المكان الاول (المطار) هويته يمنحها لأمكنة غايرته كالسينما وغيرها، لذلك فقد كان الحلم هو الرابط الاساس في صناعة امكنة هتروتوبيا داخل المكان ، وهو ما يتحقق فيه رأي ميثيل فوكو في الهتروتوبيا حيث قصد ان الهتروتوبيا ايجاد الأمكان (المتخيل) في المكان الواقعي المادي وان كان حلمًا او تخيلًا. وتتكثف خيوط اللعبة من خلال تدحرج اربعة حقائب سفر في اتجاهات مختلف ثم تبدا بقوه ، ثم يبدا يخيم الصمت اصوات اقدام ودخول ثلاث اشخاص وامرأة يتحركون بريبه احدهم يرصد الاخر تثدهم رغبة بفعل شيء، كل واحد منهم يريد ان يتصدر الدخول لتبدا لعبة الصراع على من يكون الاول في الدخول لينهي الصراع بأن كلهم يرفعون حقائب السفر ويصرخوا دون ان نعرف من سوف يكون الاول حث يحمم الصراع ، عندما يذخل الرجل الصامت الذي يمثل الاخر المتضخم ليحسم الموقف، حيث يبدأ السماح لهم بالدخول وفق شروطه هو وليس شروطهم فهو الذي يقرر من المسموح ولا المسموح. (الانا المتضخمة) التي تدير اللعبة وهو يجلب حاوية ليضع كل من هؤلاء ادواته التي جلبها معه، لذا هناك جهاز سونار هو من يتحكم بالسماح للدخول وفق شروطه والتي عبر عنها العرض حيث يدخل الرجل المثقف ليدخل فجهاز السونار يشير الى المنع يخلع شفتـه فيرفض الجهاز دخوله ثم يلقي بالكتاب في السلة يأذن له الجاهز بالدخول وكذلك رجل الدين الذي يضع لحته المزيفة والسبحة في السلة، كي يمرر خطابه، فالجهاز التي تديره (الانا المتضخمة) وهي الانا تمثل غياب / حضور حيث يشكل حضورها بما تفرضه من صرامة في استخدام تقنيات للهيمنة، وهي تمثل حالة غياب لان حضورها كهيمنة غير محدودة المعالم يبرزها العرض من خلال ما يحيط بها من صرامة تظهر من خلال مغردات العرض المبثوثه في فضاء الخشبة من حركة ولون واضاءه وموسيقا. يبدا العرض يؤسس حضوره من تلك اللحظة الحاسمة التي ينبق منها الحدث من خلال اشتغال منظومة التقنيات لتحقيق تلك الامكنة التي يسبح في فضاءها العرض واستثمار اللون والموسيقا لتحقيق وبث شفرات العرض ليثكل لنا عرض يستفز وجودنا ، وهو الفضاء الثقافي الذي انتج لنا تلك الاتساق التي وجدت نفسها تعيش تلك المحنة ، محنة ما بعد السقوط المريع لأبشع نظام عرفته المنطقة فالعرض يمتزج به الخيالي بالغرائبي من حيث مضمونه السياسي الذي يعبر عن واقعنا الذي يثبه بالفلم الكارتوني الذي يطلق العنان الى المخيلة.

يبدا العرض يبث لنا شفراته لذا فان الحدث يدور في طائرة بدون هدف ليكتشف الجميع ان الطائرة بدون طيار، غياب الطيار غير معلوم وليس له هدف ليكتثف هؤلاء انهم في محنة حقيقية ليضعنا العرض امام فرضية الاختيار الذي يجب ان يقره هؤلاء الركاب ، وهو الخيار الذي يتخذونه امام هذا الموقف الذي وجدوا انفسه مشدودون اليه وهو كناية امام رغبات وامزجة هؤلاء حيث يبدا الصراع حول ماذا يفعلون بالطائرة كل يريد ان يحقق حلمه من هذه الطائرة التي تحلق في الهواء ولا احد يدري متى تتزل وكيف تتزل، وهل هبوطها سوف يغرق الجميع انها تساؤلات تبقى تستثز الجميع · 
ويأتي انتقال اخر الى مكان اخر وهو (السرير) ادخله امن المطار حيث يتم اعلان عن موت رجل الدين الا انه كان في غييوبة ويتجمع الكل تحت السرير وينهض ليحول المؤمن (رجل الدين) سرير المستشفى الى منبر واعلاء فتاواه وهو يتربع على منبره

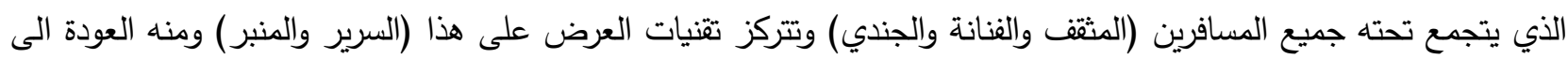

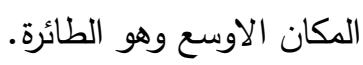

ثم تتنقل الى ساحة المعركة داخل الطائرة وهي في الفضاء، وحقائبهم تتحول الى مواضع

قتال وتكرار الجندي لكلمة (نفهم ، نفسهم وهو يمشي مشيًا عسكرًا) حيث يلتقي برجل امن الطائرة يقدم له التحية وهو يقول:

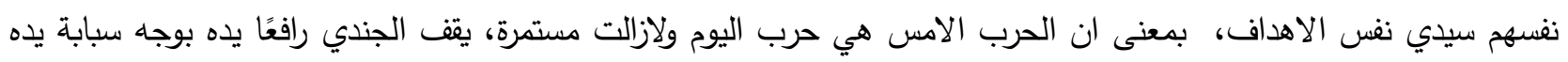

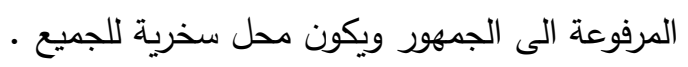
لازلنا كمتلقين مع الفضاء والحرب وادانتها ومن مكان الى اخر ومن فضاء الى اخر وتحت ذات الدكان (الطائرة) تصيح المطربة فيهم (الإفندية) والمقصود رجال الحرب، وهنا يتحول السرير الى خشبة مسرح عندما ترتقيه الفنانة وهي تقول (من كبل جنت اصعد المسرح). (20) استطاع العرض ان يؤسس رؤيا جمالية ممزوجة بالمغايرة وباستثماره تقنيات الاداء لاى الممثلين من خلال لغة الجسد والخطاب اللغوي الذي بداء ييث مثيراته باستخدام الإضاءة كمثير بصري كاثفا من خلالها تتوع الامكنة ناقلنا من مكان الى اخر فالعرض قائم على تلك اللعبة كاشف لنا بلاغة تلك الككونات التقنية وبساطتها حيث يدور العرض في مكانين قاعة المطار التي يدور فيها المشهد الاول باستخدام الحقائب التي تعطي لنا هوية للمكان الذي ينطلق منه العرض فاستثمار الحقيبة وجهاز الكثف عن الممنوعات الذي وظفه العرض كتقنية متعددة الدلالات والعلامات، لغرض انتاج صور لها مرجعيات في ذاكرة المتلقي واضافة

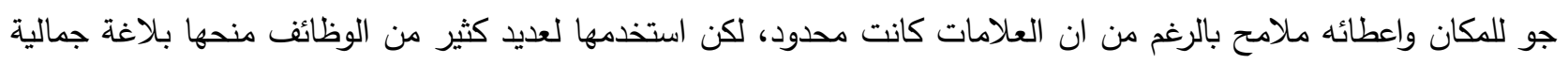

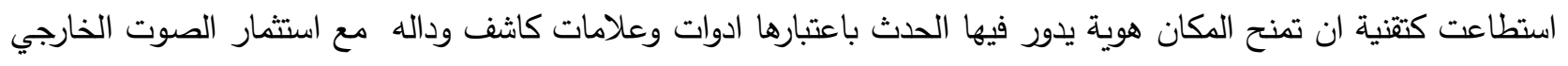
كتقنية.

استطاع العرض ان يمنح المكان حضور ، فالأدوات التي استثمرها المثل ادت دورا اساسيا للتحليق بالعمل واعطاءه صبغه جمالية، فالتحولات العديدة في كثير من المشاهد لخلق مكان وهوية، اذ سرعان ما تحولت الحقيبة من حقبة سفر للملابس الى لى موضع دفاعي في الحرب، لذا عملت التقنيات وتحولاتها الى خلق تتوع بالأمكنة وتتوعنها، فقد نقلتنا بساطة التقنية الى جو مونه الطائرة التي هي كناية عن الوطن الذي يقوده طيار مجهول، لم يفصح عن هويته. ومن خلال المكان الذي عبر عنه العرض من بإحاطة خشبة العرض بنايلون اذ لعبت فيه الإضاءة دورا مهما في تحديد هوية المكان داخل الطائرة، وكذلك استطاع الضوء ان يحدد لنا غرفة الطيار وهو لم يفصح عن هويته اي ان هناك حضور / وغياب حضور غرفة القيادة كمكان محدد، وفي نفس الوقت مارس غياب لعدم معرفة هوية الطيار الذي بقي حتى النهاية غير معلوم، 
وكذلك خلق التتافر بين الثخصيات الذين ينتمون الى هويات مختلفة من خلال جمالية الاداء وتحولات الممثلين من حال الى اخر والذي كثف عن التناقض الذي حل بهؤلاء والتي تكثفت عندما وجدوا انفهم في داخل تلك الرحلة مما كثف عن تصادمهم كذوات محطمة وجدت نفسها في رحلة مجهولة المكان داخلها.

يدور صراع مرير بين الثخصيات تتبادل الادوار فيما بينها لتمثل دور الجلاد والضحية، حيث يقدمه لنا العرض بتقنية اداء ماهرة بين رجل الدين والمثقف اليساري الذي كثف الصراع النفسي في داخل تلك الرحلة التي هي كناية عن الوضع الذي يعيشه مجتمعنا في توجه التهم واسقاط الاخر وتمثيل دور الضحية والجلاد من خلال تداول السلطة، وهي قراءة لواقعنا التاريخي والسياسي المتأزم الذي انتج لنا خطاب الكراهية

لقد بلغ استعمال الموسيقا والمؤثرات حد الدقة خاصة في مشاهد الصراع العنيف، ان استخدام الموسيقا الجيدة والمناسبة في العرض المسرحي، لا تساعد المشاهدين فقط على الاستمتاع بالعرض بل تساعد كذلك الممثل على أن يبرز طاقاته من خلال إعطائه مساحه للأداء وإظهار مرونة جسمه، وهذا ما تم فعله في اغلب المشاهد، اذ اخذت الموسيقا والمؤثرات الصوتية دورهما في التعبير عن المواقف وابرازها وتأكيد واقعيتها، لقد وفق العرض باستخدام الموسيقا والمؤثرات الصوتية، ولم يكن هناك مبالغة في استخدامهما، خلال تصميم مجموعة من المعزوفات المختلفة التي تجمعها وحدة موضوع وهي فكرة العمل المسرحي، واستطاعت أن نكون دراما موسيقية متكاملة عززت مصداقية الصراعات بين الخير والثر او الحزن والفرح.

ساعدت الموسيقا والمؤثرات الصوتية في دعم الصورة الإيقاعية للعرض والتي اعطت فيما بعد قدرة المحاكاة الحقيقية او الصدى الحقيقي للموسيقا الداخلية للعرض المسرحي وكانت عنصر مهم في إيصال الأفكار إلى المتفرجين، وما تتتجهُ هذه العملية من تأثيرات حسية ونفية في إضفاء الجو الروحي العام للعرض المسرحي وهما معًا الموسيقا واللغة التعبيرية للجسد يحددان إيقاع المشهد وبالتالي من إيقاعات المشهد يتحدد إيقاع المسرحية ككل.

لقد وضع العرض مجموعه من الاشكاليات التي تعصف بمجتمع ما بعد السقوط هي ثيمات افرزتها ثقافة التهميش والاقصاء مجموعه من العلل التي ورثها واقنعنا السياسي وانتجتها العقلية القعية لتجد نفسها في محنة حقيقية المغنية التي هي كناية عن الخطاب الفني والتي تحمل في داخلها القيم الجمالية حيث تجد نفسيها في هذه الرحلة القلقة والتي تريد ان تجد ذاتها في واقع لا يمكن ان يحقق ذلك ما دام قائد الرحلة غير معلوم وما دامت الاهواء تعصف بتلك الشرائح الاجتماعية الذي سلط عليها العرض مبضع التشريح الفصل الرابع النتائج نتائج البحث ومناقثتها بناءً على ما جاء من تحليل عينة البحث، تم التوصل الى النتائج الآتية: 
1- تقانة الاداء عند الممثل يلعب دور مهم في تحديد وتشكيل هوية المكان واعطاهه جمالية بالرغم من فقر السينوغرافيا، الذي لعب فيه الاداء دور اساسي في كثف هوية المكان ومتغيراته وهو الطائرة وساحة المطار •

ץ-تعد (الانا المتضخمة ) هي النسق الفاعل في خلق هوية المكان والتي تعمل على جذب المتلقي لتحديد هويته واعطاء خصوصية من خلال ما يقترحه من أداءاه تسهم في خلق بيئية متغايرة كما في عرض يا رب واقتراحه عدة حلول باستخدام

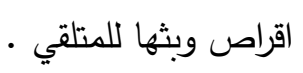

r- تسهم التقنية في خلق امكنة درامية متعدد لصياغة جماليات العرض التي تعمل على منح العرض امكنة متغايرة يلعب فيها المثير التقني دور اساسي وجمالي.

ع-تعمل التقنية على منح المتلقي امكنه متغايرة يتثكل من خلالها العرض وجمالياته ومنحه فضاءات تأوليه . ه- تسهم التقنيات على منح امكنة متغايرة والتي يتشكل من خلالها العرض وجمالياته في خلق فضاءات تأويلية للعرض لكل فضاء علاماته فضاء افتراض وفضاء مجازي وفضاء العرض •

1- تسهم التقنيات بخلق علامات متعددة الدلالات لغرض انتاج صور لها مرجعيات في الذاكرة الجمعية مما تعمل على اعطاء ملامح للمكان يسهم المتلقي في تخليه كعرض احلام كارتون الذي وظف الحقائب كعلامات كاشفة لهوية المكان V- تثتغل التقنيات كفضاء تأويلي من خلال عملها على اكثر من بؤرة لغرض خلق رؤيا جمالية متعددة التأويلات محملة بخطابات مختلفة. الاستتتاجات.

$$
\text { في ضوء نتائج البحث التي تم التوصل اليها، استتتج الباحثان الآتي: }
$$

1- تعمل التقنيات المسرحية بقصدية جمالية لخلق تغاير صوري تتشكل من خلاله الامكنة داخل الفضاء المغلق والفضاء • المفتوح

r- تظهر جماليات التقنيات بشكل فعال عندما توظف في السرد البصري ، ويخلق التطور التقني دورًا في تطوير الامكنة المتغايرة وتتوعها .

r- تعمل التقنيات كمثير لغوي ومثير صوري من خلال جديلة الهحم والبناء فهي تسهم في اخفاء عيوب الاداء في حالة هينة المثير الصوري على اللغوي وكذلك اخفاء المثير البصري وابراز المثير الصوري . n ع- تكمن بلاغة المتغاير عندما يشتغل في عدة بؤر جمالية مناحا المكان روى مختلفة، فالثكل الصوري يحقق التغاير المكاني الجمالي والفني بعيدًا عن الجانب السمعي (مؤثرات موسيقية او صوتية). 
ه- ان توجه المخرج العراقي نحو تصوير اكثر من مكان داخل خشبة المسرح انما لغرض تحقيق الخروج عن مألوف ومعتاد عليه من قبل المتلقي العراقي وبالتالي تحقيق متعة جمالية . التوصيات.

في ضوء ما توصل اليه من النتائج والاستتتاجات، يوصي الباحثان بالآتي: 1- اقامة مهرجانات فنية تهتم بأهمية المكان في العروض المسرحية تأكيد دور التقنيات في تكوينها . ץ- اهمية معرفة علاقة المكان بتقنيات المسرحية بكونها تمنحهم هويته وملامحه واهميته بالنسبة لطلبة الفنون الجميلة في كافة •خصصاتهم المقترحات.

$$
\begin{aligned}
& \text { استكمالًا لمتطلبات البحث نقترح اجراء الدراسات الآتية. } \\
& \text { ا ـ دراسة الامكنة المتغايرة في النص المسرحي العراقي • } \\
& \text { r- دراسة الامكنة المتغايرة في الفضاءات المفتوحة . }
\end{aligned}
$$

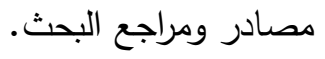

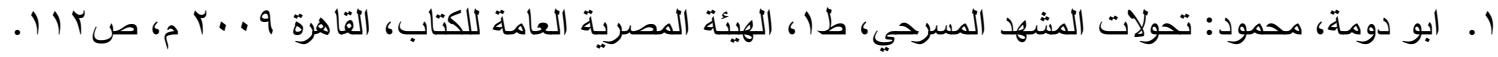
r. البراك، ياسر عبد الصاحب: الدراما تؤرخ في المسرح (قاسم محمد انموجًا)، مجلة الخشبة، العدد ب-؛ ، بغداد، مركز روابط

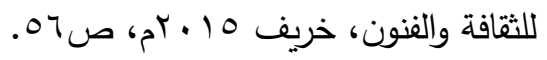

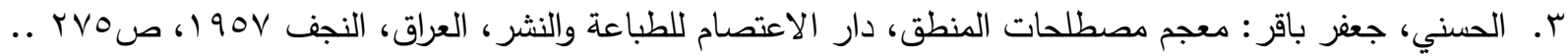
ـ. خضير ، محمد: بصرياثا صورة مدينة، ط (، منشورات الأمد، بغدادس99 (م، ص 10 (.

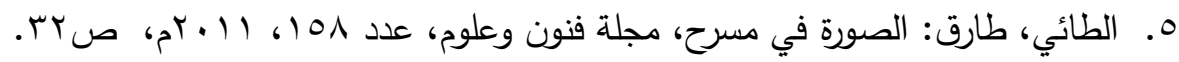

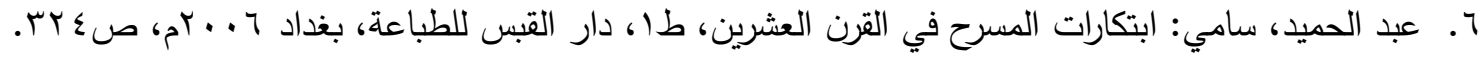
V. العبودي، جبار جودي: السينوغرافيا (المفهوم - العناصر - الجماليات) ، طا، دار ومطبعة عدنان، بغداد 1 ـ. م م، صמא. A. علي، عواد: هاملت في المختبر التجريبي العربي، مجلة شانو، العدد IV، السنة الثالثة فرقة مسرح سالار، السليمانية،

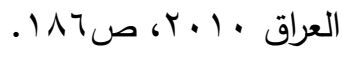




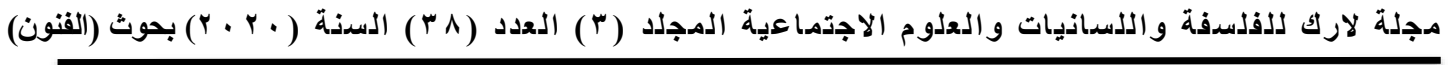

9 . كاي، ني: ما بعد الحداثة والفنون الادائية، تر ، نهاد صليحة، طץ، الهيئة المصرية العامة للكتاب، مصر 99 ام، ص797.

• ( ـشهدي، ريم: المسرح يجمع الموت والدمار ويعبر الرؤى لتجنب المآسي، موقع المستقبل، الجمعة VY شباط ، ؟ ... https://almustaqbal.com.

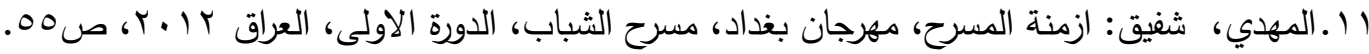

Y ا ـوليامز، دافيد: مسرح الثمس، تر ، امين الرباط، مركز اللغات والترجمة، القاهرة 999 ام صك ا. 